\section{RESENHA DO LIVRO POLÍTICAS PÚBLICAS DE ESPORTE/LAZER E IN(EX)CLUSÃO DE PESSOAS COM DEFICIÊNCIA}

\author{
REVIEW OF THE BOOK POLÍTICAS PÚBLICAS DE ESPORTE/LAZER E IN(EX) \\ CLUSÃO DE PESSOAS COM DEFICIÊNCIA
}

\begin{abstract}
RESEÑA DEL LIBRO "POLÍTICAS PÚBLICAS DE DEPORTE/OCIO E IN(EX) CLUSIÓN DE PERSONAS CON DISCAPACIDAD"
\end{abstract}

\author{
Rafael Estevam Reis*, Marcelo Moraes e Silva*, Tabea Epp Kuster Alves*, \\ Fernando Marinho Mezzadri*
}

Palavras chave:

Políticas públicas. Esportes.

Pessoas com

deficiência.

Iniquidade social.

Keywords:

Public Policy.

Sports.

Disabled persons.

Social inequality.

Palabras clave: Políticas Públicas. Deportes.

Personas con

discapacidad. Inequidad social.
Resumo: Trata-se de uma resenha do livro Políticas Públicas de esporte/lazer e in(ex) clusão de pessoas com deficiência, escrito por Júnior Vagner Pereira da Silva e publicado pela Editora da UFMS no ano de 2015. Destaca-se a temática, principalmente por abordar a inexistência da inclusão da pessoa com deficiência nas práticas de esporte e lazer nos parques esportivos da cidade de Campo Grande. A pesquisa refere-se apenas a uma realidade local, porém a grande maioria dos resultados obtidos na capital sul matogrossense não é diferente de outras cidades e estados do Brasil. Sendo assim, o livro resenhado torna-se uma importante contribuição para o campo das políticas públicas de esporte e lazer para os indivíduos com deficiência.

\begin{abstract}
This is a review of Júnior Vagner Pereira da Silva's Políticas Públicas de Esporte/Lazer e In(Ex)Clusão de Pessoas com Deficiência, published by Editora da UFMS in 2015. The theme focuses on the lack of inclusion of disabled people in sport and leisure practices at sports parks of the city of Campo Grande. The study refers only to a local reality, but most results obtained in the state capital of Mato Grosso do Sul are similar to other Brazilian cities and states. Thus, the book becomes an important contribution to the field of public policy for sport and leisure for disabled people.
\end{abstract}

Resumen: Esta es una reseña del libro "Políticas públicas de deporte/ocio e in(ex)clusión de personas con discapacidad" escrito por Júnior Vagner Pereira da Silva y publicado por la Editora de la UFMS en el año 2015. El tema se destaca principalmente por abordar el problema de la falta de inclusión de las personas discapacitadas en las actividades de deporte y ocio en los parques deportivos de la ciudad de Campo Grande. El estudio se refiere solamente a una realidad local, pero la gran mayoría de los resultados obtenidos en la capital de Mato Grosso do Sul no difieren de otras ciudades y estados de Brasil. Por lo tanto, el libro reseñado se convierte en una importante contribución para el campo de las políticas públicas de deportes y ocio para personas con discapacidad.
*Universidade Federal do Paraná. Curitiba, PR, Brasil. E-mail: rafael_e_reis@ hotmail.com

Recebido em: 08-01-2016 Aprovado em: 26-08-2016

(c) (i) (8) Licence 
O livro Políticas Públicas de esporte/lazer e in(ex)clusão de pessoas com deficiência é uma obra escrita por Júnior Vagner Pereira da Silva, docente da Universidade Federal do Mato Grosso do Sul (UFMS), e foi publicado pela Editora da UFMS no ano de 2015. Percebe-se a provocação do autor já no título da obra, quando faz um jogo de palavras, indagando se de fato tais políticas servem como instrumentos de inclusão dos indivíduos com deficiência.

Para alcançar seu intento, Pereira da Silva divide o livro em quatro capítulos, além da conclusão. No primeiro capítulo o autor expõe os aspectos introdutórios de sua pesquisa, momento no qual apresenta a problemática da obra. No segundo capítulo, intitulado "Pessoas com deficiência, era dos direitos e políticas públicas", o autor resgata historicamente a construção dos direitos dos indivíduos com deficiência. Já no terceiro capítulo, denominado "Dimensões da acessibilidade e inclusão de pessoas com deficiência nos esportes", Pereira da Silva se preocupa em salientar os diferentes conceitos e significados por trás do termo "acessibilidade", bem como entender a importância de tais definições para compreender e analisar os dados levantados no capítulo seguinte. No quarto e último capítulo o autor apresenta a metodologia utilizada no trecho final da pesquisa, bem como os resultados alcançados, analisando os "Parques esportivos de Campo Grande/MS como espaço e lugar de in(ex)clusão de pessoas com deficiência física e visual", assim como aponta o título do capítulo.

No capítulo dois, o livro mostra como a luta pelos direitos dos indivíduos com deficiência é uma batalha travada há um longo tempo. Uma jornada desgastante e repleta de altos e baixos. Pereira da Silva lembra que a preocupação com a referida temática inicia-se na França em 1789, através da "Declaração dos Direitos do Homem e Cidadão". Entretanto, conforme aponta o autor, a universalização dos direitos humanos somente ganha força em 1948, quando a Organização das Nações Unidas (ONU) aprova a "Declaração Universal dos Direitos Humanos". O autor ainda salienta que durante toda essa trajetória o indivíduo com deficiência esteve ao lado dos grupos excluídos da sociedade, como os pobres, os homossexuais, as mulheres e os idosos.

Ainda nesse capítulo, é apresentada uma série de declarações internacionais e nacionais que desde 1975 visam auxiliar no processo de inclusão dos indivíduos com deficiência. São elas: "Declaração dos Direitos das Pessoas com Deficiência"; "Declaração de Salamanca"; "Declaração Internacional de Montreal sobre inclusão"; "Convenção Internacional sobre os Direitos das Pessoas com Deficiência"; e "Constituição Federal". Para finalizar o capítulo, Pereira da Silva concentra seus esforços em explicar melhor algumas questões voltadas para o âmbito das políticas públicas. Explora também as questões legais e jurídicas que cercam esse universo. Nessa parte do livro o autor foca seus esforços na análise de uma agenda política, discutindo se a temática merece a atenção dos governantes para se tornarem políticas públicas. Mostra que sob uma ótica neoliberal, aliada a um sistema de governo com "recursos insuficientes", as ações são pensadas e aplicadas basicamente aos direitos fundamentais como educação, saúde e segurança, marginalizando, por exemplo, ações voltadas ao esporte e lazer.

O capítulo três propõe discutir questões de acessibilidade no cenário esportivo. Suas preocupações se centram tanto no aspecto arquitetônico como nas temáticas comunicacionais, instrumentais, psicológicas, atitudinais, programáticas e metodológicas a serem utilizadas nas ações que serão realizadas com os indivíduos com deficiência. No que tange à dimensão arquitetônica, Pereira da Silva relembra que esse público por muito tempo esteve alocado à 
margem da sociedade, e que as construções arquitetônicas quase sempre foram pensadas e edificadas seguindo a ideologia do "homem-padrão". O autor lembra ainda que, ao longo dos anos, diversos países começaram a discutir a questão da acessibilidade arquitetônica até chegarem ao conceito de "Desenho livre de barreiras", que tem como principal intuito adaptar espaços urbanos para indivíduos que apresentem mobilidade reduzida. No Brasil, essa discussão chegou com força na década de 1980 - através da Constituição Federal de 1988 - e nos anos seguintes com a promulgação da Carta Magna brasileira e a elaboração da Norma Técnica Brasileira (NBR9050), que tem como intuito adequar as construções já existentes para o uso de indivíduos com deficiência.

Outro conceito importante levantado por Pereira da Silva nesse capítulo é sobre a acessibilidade pautada no desenho universal, que tem como objetivo eliminar qualquer tipo de barreira que impeça 0 direito de ir e vir, enfatizando que tal conceituação defende 0 acesso a todos, e não somente aos indivíduos com algum tipo de deficiência. $O$ autor relembra que esse conceito também engloba questões de atendimento adequado, vagas de estacionamento, serviços telefônicos, sinalização em braile, dentre outros pontos importantes. Tal fato não difere em relação ao esporte e lazer, afinal, espaços como praças, parques, teatros, estádios e campos devem estar adaptados e em condições adequadas a receberem indivíduos com deficiência. Ainda neste capítulo, o autor aborda três dimensões da acessibilidade para os esportes adaptados: metodológica, instrumental e programática. A primeira significa adaptar uma atividade para que um público específico possa ser atendido. Este seria o caso das modalidades paradesportivas, adaptadas de uma já existente, como, por exemplo, o futebol, ou ainda de esportes que não derivaram de nenhum outro, caso do Goalball. Nesse momento, Pereira da Silva faz a relação da acessibilidade metodológica com a instrumental, que se caracteriza pela remoção de barreiras para utilização de instrumentos e equipamentos. Por fim, o autor enfoca sua análise na programática que pode ser percebida na ausência de atividades propostas em parques e clubes de esporte e lazer para indivíduos com deficiência.

Na sequência, o autor aprofunda-se nas modalidades paradesportivas. 0 processo de adaptar e/ou criar um esporte nada mais é do que o conceito de acessibilidade sendo instaurado no âmbito esportivo. Em primeiro lugar são apresentadas as modalidades paralímpicas de verão (22 no total): Atletismo; Basquetebol em Cadeira de Rodas; Bocha; Canoagem; Ciclismo; Esgrima; Futebol de 5; Futebol de 7; Goalball; Halterofilismo; Hipismo; Judô; Natação; Remo; Rúgbi em Cadeira de Rodas; Tênis em Cadeira de Rodas; Tênis de Mesa; Tiro com Arco; Tiro Esportivo; Triatlo; Vela; e Vôlei sentado. Pereira da Silva apresenta esses esportes paralímpicos num quadro no qual demonstra 0 ano em que a modalidade foi introduzida nos jogos, assim como o tipo de deficiência que a abrange. $O$ autor ainda traz informações sobre os esportes paralímpicos de inverno: Esqui Alpino; Biatlo; Esqui Cross-Country; Hóquei no Gelo sobre Trenó; e Curling em Cadeira de Rodas. Ainda nesse tópico, são trabalhados os esportes adaptados não paralímpicos e os de aventura. Pereira da Silva salienta a importância dessas modalidades que, mesmo não estando credenciadas ao Comitê Paralímpico Internacional, prestam um importante serviço aos indivíduos com deficiência.

No último capítulo, o autor realiza um levantamento histórico-geográfico da cidade de Campo Grande, apresentando elementos relacionados ao desenvolvimento urbano da capital sul-mato-grossense. Essas informações são importantes para a construção da ideia que Pereira da Silva levantará mais adiante sobre as políticas públicas para o esporte e lazer para 
os indivíduos com deficiência, como a divisão dos bairros e suas características, o contingente populacional com deficiência e quais os tipos de deficiência que prevalecem, reforçando alguns dispositivos legais que garantem - ao menos no plano da legislação - uma série de direitos aos indivíduos com deficiência no que tange à prática de esportes e lazer dentro do município. Tão importantes quanto os aspectos levantados, os caminhos metodológicos usados no livro ajudam a compreender as rotas trilhadas por Pereira da Silva para responder seus anseios e dilemas de pesquisa. Com este fim, o autor utiliza como técnica de investigação a avaliação morfológica normativa, que tem como função compreender a formação física da cidade e todos os seus componentes elementares. Ação que se concretizou através da observação direta por parte do pesquisador nas dependências dos diversos parques esportivos do município. A fim de coletar as informações, foi adotado pelo autor um checklist de vistoria, que foi idealizado pela Secretaria Municipal de Pessoa com Deficiência e Mobilidade Reduzida de São Paulo. Já a referência para realizar a análise foi baseada nas "Normas Brasileiras para Acessibilidade, a Edificação, Mobiliário, Espaços e Equipamentos Urbanos (NBR9050/2004)".

Pereira da Silva lembra que qualquer tipo de alteração arquitetônica ampara-se em dispositivos legais, utilizando-se em sua pesquisa das leis, estatutos, decretos e normas. Sendo assim, documentos importantes como o "Estatuto da Cidade" e "Plano Diretor e Política de Desenvolvimento Urbano de Campo Grande" foram selecionados como um importante conjunto de fontes. Para avaliar os programas desenvolvidos nos parques, foram utilizadas entrevistas estruturadas com três coordenadores de projetos e dois presidentes de Organizações Não Governamentais (ONGs). A pesquisa selecionou cinco parques, um em cada região de Campo Grande, podendo, desta forma, se deparar com realidades mais diversas, tornando a pesquisa mais abrangente.

Na parte final deste capítulo, Pereira da Silva descreve minuciosamente a questão de acessibilidade arquitetônica dos espaços esportivos selecionados. Sem a intenção de concluir, mas já deixando alguns sinais da realidade dos parques esportivos da cidade de Campo Grande, o autor analisa os passeios públicos, os acessos, os locais de circulação, sanitários e vestiários, mobiliários e estacionamentos. Sendo assim, é possível detectar, através da escrita do autor, a inconformidade com a situação dos parques esportivos de Campo Grande, visto que não estão, conforme aponta o plano legal, nos padrões para o acesso dos indivíduos com deficiência.

O livro ainda traz outras pesquisas desenvolvidas em diferentes locais, mas que apresentaram objetivos similares. Os estudos realizados em Salvador/BA, Irati/PR e Natal/ RN, além de países como Espanha, Portugal e Canadá, também apresentam resultados desanimadores no que concerne à acessibilidade arquitetônica em parques esportivos. Esses exemplos vêm para corroborar a afirmação de que existem, pelo menos no plano legal, inúmeras ações em relação à acessibilidade arquitetônica sendo desenvolvidas. Contudo, a efetivação dessas políticas públicas não acontece da forma como foram pensadas do ponto de vista legislativo. Ao refletir sobre essa questão o autor levanta duas possibilidades de compreensão para tal quadro: a) existe uma concepção restrita em relação à acessibilidade, limitada basicamente à criação de rampas; b) ocorre justamente um entendimento incompleto sobre o tema, como, por exemplo, a adaptação incompleta de um espaço, como um banheiro adaptado sem as barras de apoio instaladas.

Para dar sequência à sua análise, Pereira da Silva trata da acessibilidade programática. Com a mesma clareza e cuidado com que analisou as questões arquitetônicas o autor reflete 
sobre as atividades e programas esportivos realizados nos parques esportivos pesquisados. $O$ autor mais uma vez percebe que a situação não é animadora, pois nenhum desses locais apresenta ação voltada aos indivíduos com deficiência. Fato que torna a acessibilidade programática inexistente. Aponta ainda que tais questões não se materializam pelo fato das políticas públicas brasileiras, em sua grande maioria, preconizarem programas que possam atender a um grande contingente populacional e por isso não têm cuidado com grupos minoritários do ponto de vista social. Para contornar essa situação, Pereira da Silva cita como exemplo as ações capitaneadas pelo Comitê Paralímpico Brasileiro (CPB), que há algum tempo vem realizando ações em parceria com o poder público para que os indivíduos com deficiência sejam incluídos nas agendas de ações dos parques esportivos nos diversos municípios brasileiros.

Em suas conclusões, o autor enfatiza a inexistência da inclusão dos indivíduos com deficiência nas práticas de esporte e lazer nos parques esportivos da cidade de Campo Grande. Seja pelas barreiras impostas pela falta de acessibilidade arquitetônica, seja pela inexistência de ações e políticas públicas voltadas para atividades paradesportivas, o livro sinaliza a falta de acessibilidade programática. Uma possibilidade sugerida por Pereira da Silva seria por intermédio da ação do Ministério Público, pois existem relatos em outros locais em que a intervenção de tal órgão governamental tem rendido alguns resultados mais imediatos aos entes públicos que não vêm cumprindo o que está posto nos diversos dispositivos legais.

A pesquisa de Junior Vagner Pereira da Silva refere-se apenas a uma realidade local, porém a grande maioria dos resultados obtidos em Campo Grande não deve ser diferente do restante das cidades e estados do Brasil. Muito pelo contrário, a falta de ações voltadas aos indivíduos com deficiência estende-se por todo o país, e as questões de acessibilidade principalmente as programáticas - quase nunca entram nas discussões relativas à elaboração de políticas públicas. Sendo assim, o livro resenhado torna-se uma importante contribuição para o campo das políticas públicas de esporte e lazer.

\section{REFERÊNCIA}

PEREIRA DA SILVA, Junior Vagner. Políticas públicas de esporte/lazer e in(ex)clusão de pessoas com deficiência. Campo Grande: Editora UFMS, 2015. 
